\title{
Las buenas intenciones no bastan: la política exterior de Estados Unidos hacia América Latina en el siglo XX
}

\section{Good Intentions are not enough: United States Foreign Policy Toward Latin America in the Twentieth Century}

NORBERTO BARRETO VELÁZQUEZ

Universidad del Pacifico

barreto_n@up.edu.pe

RESUMEN

Este ensayo examina los múltiples intentos realizados por el gobierno estadounidense a lo largo del siglo XX para mejorar sus relaciones con América Latina. La mayoría de estos fueron causados por factores externos como guerras o conflictos con otras potencias. Aunque sinceras, estas iniciativas fracasaron ante las prioridades geopoliticas y económicas de la politica exterior estadounidense. Elementos raciales y, principalmente, la ignorancia de los policy makers estadounidenses en asuntos latinoamericanos también determinaron el poco éxito de tales iniciativas. Concluimos que las buenas intenciones no son suficientes para que una potencia mundial logre comportarse como un buen vecino.

Palabras clave: intervencionismo, intereses económicos, intereses geopoliticos, determinismo ideológico, racismo.

\section{ABSTRACT}

This essay examines the US government's attempts throughout the $20^{\text {th }}$ century to improve its relations with Latin America. It shows that most of these efforts were motivated by external factors such as wars or conflicts with other world powers. 
Although genuine, these attempts were ultimately subordinate to the United States' geopolitical and economic foreign policy priorities. Racial elements and, especially, the ignorance of US policymakers dedicated to Latin American affairs, played a role in limiting the success of US initiatives. The essay concludes that a world power's good intentions alone do not qualify as behaving like a good neighbor.

Keywords: Interventionism, Economic interests, Geopolitical interests, Ideological Determinism, Racism.

Cl principal objetivo de este trabajo es promover una discusión abierta América Latina, que permita reconocer que no todas las acciones estadounidenses en la región tuvieron una finalidad perversa. ${ }^{1}$ A lo largo del siglo XX, Estados Unidos buscó ser un buen vecino al promover el progreso económico, la democracia y la estabilidad política entre los países latinoamericanos. Sin embargo, las buenas intenciones no fueron

1 Durante la revisión de los comentarios de los evaluadores de este texto, tropecé con una mesa redonda de $\mathrm{H}$-Diplo sobre la más reciente obra del historiador estadounidense Lars Schoultz, titulada In Their Best Interests: A History of the U.S. Effort to Improve Latin Americans (Cambridge: University of Harvard Press, 2018) Desafortunadamente, no he tenido acceso al libro, pero por los comentarios de los historiadores que participaron en esta discusión, es claro que su autor argumenta que históricamente Estados Unidos ha buscado uplift (mejorar) la región latinoamericana. También he podido identificar ciertas cercanías entre el trabajo de Schoultz y el argumento de este ensayo. Ambos enfocamos los esfuerzos estadounidenses para mejorar sus relaciones con América Latina. En el caso de Schoultz, el enfoque está en los esfuerzos, no solo del gobierno, por mejorar la vida, la organización política, etc., de los latinoamericanos. Schoultz enfoca a las organizaciones sin fines de lucro, las universidades, las fundaciones, etc. En mi caso, el énfasis está puesto en las iniciativas gubernamentales para promover el progreso económico, la democracia y la estabilidad entre los países de la región. Ambos pretendemos superar la idea del imperio siniestro y enfatizar un mayor nivel de complejidad en el análisis del desarrollo histórico de la política exterior de Estados Unidos para América Latina. Ver: H-Diplo Roundtable XX-43 on Lars Schoultz. In Their Own Best Interests: A History of the U.S. Effort to Improve Latin Americans. https://networks.h-net.org/node/28443/ discussions/4207033/h-diplo-roundtable-xx-43-lars-schoultz-their-own-best-interests. Fecha de consulta: 11 de julio de 2019. 
suficientes. ${ }^{2}$ En este ensayo veremos cómo limitaciones geopolíticas e ideológicas, intereses económicos, prejuicios raciales y, especialmente, la incapacidad de los políticos estadounidenses para entender a los países latinoamericanos en sus propios términos no le permitieron a Estados Unidos ser un mejor vecino. Para ello, haré un examen general del desarrollo de las relaciones de Estados Unidos y América Latina durante el siglo XX, destacando las instancias en que hubo intentos por el vecino norteño para mejorar las relaciones y de las razones de su éxito o fracaso. ${ }^{3}$

Estoy consciente de que se podría cuestionar las buenas intenciones estadounidenses como parte de un proyecto de hegemonía imperial, pero igual sostengo que no dejaron de ser sinceras y que merecen ser tomadas en serio y, sobre todo, estudiadas y discutidas.

\section{DE LA INTERDEPENDENCIA A LA «HEGEMONÍA» YANQUI}

Desde el siglo XVIII, el destino de los países del hemisferio occidental estuvo unido por razones económicas (comercio/inversión), geográficas (cercanía) e históricas (pasado colonial). La apertura al comercio con las colonias españolas a finales del siglo XVIII conllevó el comienzo de un proceso de integración económica de la América hispana con las Trece Colonias británicas. ${ }^{4}$ Lo que más tarde será conocido como América Latina se convirtió en un mercado para los colonos del norte, gracias al llamado comercio triangular. Desde ese momento, se estableció la base de una interdependencia asimétrica en la que los latinoamericanos constituían el eslabón más vulnerable de la cadena. Después de las guerras

2 Las buenas intenciones se han manifestado a través de la promoción del multilateralismo, la búsqueda de mejores condiciones comerciales para la región, el fomento de intercambios culturales, la creación de programas de asesoría técnica y ayuda económica, el establecimiento de programas de becas, etc.

3 Es también la intención de este trabajo promover una discusión que supere la dicotomía víctima (América Latina)-victimario (Estados Unidos) que ha caracterizado buena parte de los análisis de las relaciones de Estados Unidos y América Latina, especialmente, por los latinoamericanos.

4 Es necesario señalar que antes de la apertura causada por las reformas borbónicas, los colonos norteamericanos mantenían relaciones comerciales con el Caribe hispano a través del contrabando. Ver Morales Carrión 2003. 
de independencia y el fin del imperio español en América, las relaciones económicas aumentaron y con ello, la desigualdad. Los nuevos países latinoamericanos se convirtieron en proveedores de materias primas para el mercado estadounidense. El desarrollo manufacturero de Estados Unidos en la primera mitad del siglo XIX aumentó la desigualdad entre las regiones. Tras la guerra civil estadounidense, la industrialización se aceleró, lo que encaminó a Estados Unidos hacia su transformación en una potencia económica y, por ende, mundial. La economía de los países latinoamericanos continuó basada en un modelo económico de exportación, cuyo nivel de especialización colocó a la región en una posición muy vulnerable ante golpes externos. ${ }^{5}$

Durante buena parte del siglo XIX, América Latina y los Estados Unidos desarrollaron una interdependencia política y diplomática, pues tenían preocupaciones similares: mantener a los europeos a raya, proteger la soberanía nacional, etc. Esto cambió a partir de la trasformación de Estados Unidos en una potencia mundial a finales del siglo XIX. La adquisición de lo que Lanny Thompson llama el imperial archipelago compuesto por Hawái, las Filipinas, Guam y Puerto Rico, cambió la situación geopolítica estadounidense. ${ }^{6}$ Las nuevas preocupaciones propias de una potencia mundial afectaron las relaciones con América Latina, especialmente, México, Centroamérica y el Caribe. Se inició así un periodo de intervencionismo en los asuntos internos de países vecinos, que llevó a la ocupación militar de varios de ellos.

A lo largo del siglo XX, Estados Unidos recurrió a varios mecanismos para ejercer su hegemonía en la región: la intervención y/o ocupación militar, las operaciones encubiertas, su poder económico (dollar diplomacy), su control de organizaciones regionales como la OEA, su influencia en organismos internacionales como el Fondo Monetario Internacional o el Banco Mundial, y su poder blando. Los diferentes actores latinoamericanos no adoptaron una actitud pasiva frente a la

\footnotetext{
5 Longley 2002: 1-6.

6 Thompson 2010. A esta lista es necesario añadir a Cuba que, como consecuencia de la Enmiendan Platt, fue convertida en un protectorado estadounidense.
} 
hegemonía estadounidense. Por el contrario, estos desarrollaron diversos mecanismos de resistencia como la lucha armada y el nacionalismo económico y cultural, entre otros. ${ }^{7}$ Es necesario aclarar que la hegemonía estadounidense no fue total ni absoluta, y, además, esta fue posible gracias a la colaboración de individuos, clases y/o fuerzas locales. No todos los latinoamericanos se lanzaron a las calles a gritar «Yankee go home»: muchos colaboraron y supieron aprovechar las oportunidades económicas que la interacción con el Imperio ofrecía.

Como veremos, a lo largo del siglo XX, no le fue fácil a los estadounidenses compaginar sus intereses económicos y geopolíticos — ni superar sus prejuicios raciales y condicionamientos ideológicos_ — con su deseo de mejorar las relaciones con los países latinoamericanos. En otras palabras, no les fue fácil ser un buen vecino.

\section{EL INTERVENCIONISMO}

Teodoro Roosevelt puede ser considerado el primer presidente imperial de los Estados Unidos. Su nivel de interés, conocimiento y participación en temas y asuntos internacionales es único con relación a los presidentes que le antecedieron. Rechazando el aislacionismo pregonado por los fundadores de la República, Roosevelt creía que Estados Unidos debía promover la paz y la estabilidad mundial. Estaba convencido de que solo un país sin "ambiciones imperiales» como Estados Unidos podía fungir como policía internacional en la búsqueda y preservación de un orden internacional en paz. Su política exterior estuvo caracterizada por una combinación de diplomacia e intimidación, la llamada big stick diplomacy. ${ }^{8}$

América Latina fue la región donde con más claridad fue aplicada esta política. Los objetivos de Roosevelt para América Latina eran claros: promover la paz, la estabilidad y el progreso. Preocupado por el crecimiento del poder naval alemán y consciente de que Europa se aproximaba a un abismo, Roosevelt buscó mantener a Alemania alejada del hemisferio

7 Longley 2002: 6-8.

8 Schoultz 1998: 177-204. 
occidental. Para implementar esto objetivos, el mandatario recurrió al intervencionismo y a la intimidación naval (gunboat diplomacy). La cada vez más poderosa Armada estadounidense se convirtió en un instrumento para proyectar y ejercer el poder de Estados Unidos en América Latina, sobre todo, en Centroamérica y el Caribe. ${ }^{9}$

Otro factor clave para entender la política exterior de Roosevelt - y de los Estados Unidos en general - es el racismo. Roosevelt compartía la ideología racista predominante de su momento histórico; por ello, no debe sorprender que su visión negativa de los latinoamericanos influyera en su política exterior. Para él, los latinoamericanos ocupaban una posición inferior entre los pueblos civilizados y eran racialmente incapaces para el autogobierno. ${ }^{10}$

Dos asuntos resultan claves en la política exterior de Roosevelt hacia América Latina: el llamado Corolario Roosevelt a la Doctrina Monroe y el canal de Panamá. El primero es producto del temor de los estadounidenses a que la inestabilidad, la anarquía y, sobre todo, la incapacidad de algunos países latinoamericanos para cumplir con el pago de sus deudas externas sirviera de excusa para una intervención europea. ${ }^{11}$ Los líderes estadounidenses temían que una potencia europea, especialmente Alemania, aprovechara la inestabilidad de algún país caribeño para construir una base naval y amenazar así los intereses y la seguridad de la nación norteamericana. En su discurso anual ante el Congreso en diciembre de 1906, Roosevelt definió claramente cuál era la posición de su administración ante este problema:

It is not true that the United States feels any land hunger or entertains any projects as regards the other nations of the Western Hemisphere save such as are for their welfare. All that this country desires is to see the neighboring countries stable, orderly, and prosperous. Any country whose people conduct themselves well can count upon our hearty friendship. If a nation shows that it knows how to act with reasonable efficiency and decency in social and political matters, if it keeps order and pays its obligations, it need fear no

9 Healy 1988.

${ }^{10}$ Dyer 1980: 140-141.

${ }^{11}$ Munro 1980. 
interference from the United States. Chronic wrongdoing, or an impotence which results in a general loosening of the ties of civilized society, may in America, as elsewhere, ultimately require intervention by some civilized nation, and in the Western Hemisphere the adherence of the United States to the Monroe Doctrine may force the United States, however reluctantly, in flagrant cases of such wrongdoing or impotence, to the exercise of an international police power. [...] We would interfere with them only in the last resort, and then only if it became evident that their inability or unwillingness to do justice at home and abroad had violated the rights of the United States or had invited foreign aggression to the detriment of the entire body of American nations. It is a mere truism to say that every nation, whether in America or anywhere else, which desires to maintain its freedom, its independence, must ultimately realize that the right of such independence can not be separated from the responsibility of making good use of it. ${ }^{12}$

En esta cita, Roosevelt niega cualquier interés imperialista en América Latina y deja en claro que Estados Unidos quería la prosperidad de sus vecinos. En un tono paternalista, Roosevelt señala que aquellos países latinoamericanos que se comportaran correctamente - especialmente, pagando sus deudas externas - no tenían nada que temer de Estados Unidos. Sin embargo, reclama el derecho de Estados Unidos, y la obligación como nación civilizada, a intervenir en aquellos países que no se comportaran dentro de los parámetros definidos por el presidente en su discurso. En otras palabras, Estados Unidos sería un buen vecino de aquellos países latinoamericanos que no representaran un problema o amenaza para los intereses estadounidenses.

El interés estadounidense en la construcción de un canal interoceánico en Centroamérica no comienza con Roosevelt, pero es él quien lo hace realidad. Como hemos señalado, la adquisición de un imperio insular a finales del siglo XIX alteró la posición geopolítica estadounidense, lo que a su vez provocó que se retomara el interés en la construcción de un canal. A las razones económicas que históricamente habían generado interés en la construcción de un canal interoceánico, se sumaron factores de carácter estratégico. La experiencia de la guerra con Cuba en 1898, y en especial la travesía del USS Oregon, hicieron necesaria la construcción 
de un canal que facilitara la defensa naval de un país que mira hacia dos océanos. ${ }^{13}$ Siguiendo los pasos fallidos de Ferdinand de Lessep y de la Compagnie Universelle du Canal Interocéanique de Panama, las autoridades estadounidenses iniciaron negociaciones con el gobierno de Colombia, pues Panamá era entonces una provincia colombiana, para la construcción de un canal. Las demandas económicas de los colombianos llevaron a Roosevelt a fomentar y apoyar una rebelión independentista en Panamá. El tratado que los estadounidenses imponen a los panameños en 1903 incluía condiciones más favorables para Estados Unidos que las que se habían negociado con Colombia, y permitió que se iniciara la construcción del canal, que fue inaugurado en agosto de 1914 . $^{14}$

La construcción del canal tuvo un impacto inmediato en las relaciones de Estados Unidos y América Latina, pues su defensa se convirtió en una prioridad para el gobierno estadounidense. Para ello fue «necesario» garantizar el orden en la región caribeña y centroamericana a través de intervenciones militares directas en países como Nicaragua, Haití y República Dominicana. ${ }^{15}$

El intervencionismo no fue la única herramienta usada por los Estados Unidos para proteger el canal y promover sus intereses, ya que también recurrieron a la llamada dollar diplomacy. Esta consistía en una combinación de racismo, paternalismo, preocupaciones estratégicas y buenas intenciones. Asociada a la figura de William H. Taft, quien ocupó la Casa Blanca entre 1909 y 1913, la diplomacia del dólar estaba basada

${ }^{13}$ El USS Oregon era uno de los acorazados de la Armada estadounidense. Al momento del estallido de la guerra con España en abril de 1898, este se encontraba en San Francisco. Se le ordenó reportarse al Caribe, lo que le tomó 66 largos días. Este incidente remarcó la importancia de un canal que facilitará el movimiento de la Armada estadounidense y, por ende, de la defensa las costas estadounidenses (McCullough 1977: 254).

${ }^{14}$ Lindsay-Poland 2003: 18-31.

${ }^{15}$ En las primeras décadas del siglo XX, Estados Unidos invadió y/o ocupó militarmente a varios países caribeños y centroamericanos: Nicaragua (1909-1910, 1912-1915, 19261933), Cuba (1898-1902, 1906-1909), Haití (1915-1934), República Dominicana (1916-1924) y México (1914). La más larga de esas ocupaciones es la de Puerto Rico, invadido y ocupado por los estadounidenses desde 1898. Ver Munro 1980; Langley 1983; Healy 1988: Nieto 2005 y Colby 2011. 
en el uso del poder económico estadounidense. Taft buscó evitar las intervenciones militares directas «substituting dollars for bullets». ${ }^{16} \mathrm{La}$ lógica de Taft era algo sencilla: a través de la «ayuda» estadounidense, los países latinoamericanos alcanzarían la estabilidad necesaria para promover el comercio, que a su vez traería paz, libertad y democracia, volviendo así innecesario el intervencionismo. ${ }^{17}$

La presidencia de Woodrow Wilson (1913-1921) cierra el periodo intervencionista. Wilson era un académico conservador sureńo cuya política exterior estuvo marcada por un fuerte idealismo. Wilson quería mantener a las naciones europeas fuera de las Américas y mejorar las relaciones con América Latina. Según Wilson, «We must prove ourselves their friends and champions upon terms of equality». ${ }^{18}$ Para ello, consideraba necesario evitar las intervenciones militares y fomentar la autodeterminación y democratización de los países latinoamericanos a través de elecciones. Wilson creía que Estados Unidos debía enseñar a los suramericanos "to elect good men». ${ }^{19}$

En el caso de Wilson, el paternalismo y las buenas intenciones fueron derrotadas por las realidades geopolíticas. El estallido de la Primera Guerra Mundial reafirmó la necesidad de proteger el canal de Panamá a través de la promoción de la estabilidad y el orden en la región. Esto se tradujo en un mayor nivel de intervencionismo. En 1915, los estadounidenses ocuparon Haití, donde permanecerían 19 años. Un año más tarde, intervinieron en la República Dominicana, que controlarían hasta 1924. La política exterior de Wilson estuvo también matizada por estereotipos raciales y prejuicios culturales, ya que era un fiel creyente en la incapacidad de los pueblos no blancos para el gobierno propio. ${ }^{20}$

\footnotetext{
16 «Sustituyendo balas por dólares». Traducción del autor.

${ }^{17}$ Munro 1980; Schoultz 1998 y Veeser 2002.

18 «Tenemos que demostrar que somos sus amigos y defensores en términos de igualdad» (Wilson, 1913). Traducción del autor.

${ }^{19}$ Cooper 2008: 281.

${ }^{20} \mathrm{Ib}$.
} 


\section{Los años 1920}

La política estadounidense en los años 1920 estuvo dominada por el Partido Republicano. Tres miembros de ese partido ocuparon la Casa Blanca entre 1921 y 1933: Warren G. Harding, Calvin Coolidge y Herbert Hoover. Estos mantuvieron una política exterior orientada a favorecer a las empresas estadounidenses, promoviendo el capital y la tecnología norteamericana en América Latina. Los Republicanos buscaban reducir la presencia económica europea en la región y dejaron la iniciativa en manos de capital privado con el apoyo de los Ministerios de Estado y Comercio. La banca jugó un papel importante en esta nueva fase de la diplomacia del dólar. La presencia de bancos estadounidenses aumentó y con ello el acceso a créditos. Entre 1924 y 1929, la banca privada estadounidense prestó $\$ 1,150$ mil millones a países latinoamericanos, el 32.2\% del total de sus préstamos. ${ }^{21}$ Tras la caída de la Bolsa de Valores neoyorquina en octubre 1929, los países latinoamericanos se encontraron profundamente endeudados y sin acceso a nuevos créditos.

Las inversiones norteamericanas en América Latina se duplicaron entre 1924 (\$1.5 mil millones) y 1929 (\$3.5 mil millones). ${ }^{22}$ Buena parte de este dinero fue usado para adquirir recursos mineros (Chile) y petroleros (Venezuela). El predominio económico que alcanzó Estados Unidos en América Latina fomentó la dependencia de los países menos desarrollados de la región, especialmente, los centroamericanos. Estos requerían del acceso al mercado estadounidense para sus exportaciones (azúcar, café, cacao, plátanos, etc.). En otras palabras, el crecimiento del poder económico estadounidense en América Latina afectó el crecimiento y desarrollo económico de los países de la zona, que vieron como se volvía cada vez más difícil diversificar sus economías para superar la creciente dependencia en el mercado estadounidense. Tal poder económico vino acompańado de una creciente influencia política en la región. Los Estados Unidos tendieron a favorecer gobiernos dictatoriales y autocráticos que

\footnotetext{
${ }^{21}$ Las exportaciones hacia América Latina crecieron de \$178 millones en 1924 a \$465 millones en 1927 (Longley 2002: 150-151).

${ }^{22}$ LaFeber 1989, V: 2:, 358.
} 
eran simpáticos con los intereses económicos de las empresas e inversionistas estadounidenses. ${ }^{23}$

Los líderes Republicanos de la década de 1920 identificaron el intervencionismo como un elemento clave en las relaciones con América Latina. Estos entendieron que el rechazo al intervencionismo entre los latinoamericanos era muy fuerte y que no fomentaba ni la paz ni el orden, sino la resistencia y el sentimiento antiestadounidense. En otras palabras, las intervenciones militares eran malas para las relaciones públicas y, por ende, para los negocios. Además, como consecuencia de la Primera Guerra Mundial, Europa ya no era una amenaza, causando que sea innecesaria la ocupación preventiva de países latinoamericanos. Por ello, no debe sorprender que los Republicanos evitaran las intervenciones y acabaran con la ocupación de la República Dominicana y Nicaragua. ${ }^{24}$

La antipatía de los Republicanos al intervencionismo llegó a su cenit durante la administración de Hoover con el llamado Memorándum Clark. En 1928, el Subsecretario de Estado J. Reuben Clark hizo importantes aclaraciones sobre este tema. En su Memorandum to the Monroe Doctrine, Clark alegó que las intervenciones solo estaban justificadas si eran sancionadas por el derecho internacional, es decir, para proteger la vida y propiedades de ciudadanos estadounidenses. De esta forma, Clark rechazó tanto la diplomacia del garrote como el Corolario Roosevelt a la Doctrina Monroe. ${ }^{25}$

\section{La política del Buen Vecino}

El memorándum Clark sirvió de antecedente para el mayor y más fructífero cambio en las relaciones de Estados Unidos y América Latina en el siglo XX: la Política del Buen Vecino (PBV). Para entender la PBV es necesario comenzar explicando su contexto histórico. El primer factor a tomar en cuenta es la creciente inestabilidad internacional causada por el ascenso del totalitarismo en Europa y Asia. La agresividad de las dictaduras

\footnotetext{
${ }^{23} \mathrm{O}^{\prime}$ Brien 1996.

${ }^{24}$ Hawley 1992: 51.

${ }^{25}$ Longley 2002: 165.
} 
totalitarias se tradujo en un fuerte militarismo y en un recrudecimiento de la competencia imperialista por los mercados y los recursos mundiales. La invasión japonesa de Manchuria, la invasión italiana de Etiopía, el expansionismo europeo alemán y la guerra civil española marcaron el camino hacia un enfrentamiento global. El fascismo se convirtió en una amenaza a los intereses económicos, políticos y estratégicos de Estados Unidos en América Latina. La presencia en la región de comunidades italianas, japonesas y alemanas, las simpatías fascistas y las actividades nazis preocupaban a los políticos y estrategas estadounidenses. ${ }^{26}$

A estos factores, habría que añadir la elección de Franklin D. Roosevelt a la presidencia estadounidense en 1932. Cuando Roosevelt llegó a la Casa Blanca en 1933, su prioridad era enfrentar los efectos de la Gran Depresión en la sociedad estadounidense. La complicada y peligrosa situación mundial forzó a Roosevelt a atender ineludibles temas internacionales. En el caso de América Latina, Roosevelt buscó mejorar las relaciones a través de lo que se llegó denominar como la PBV. Quería desarrollar solidaridad hemisférica, es decir, un frente común de defensa y resistencia a los países del Eje. Para ello, consideraba necesario fomentar la cooperación económica, cultural, política y militar con la región latinoamericana; además de garantizar el acceso a los mercados latinoamericanos, promoviendo una relación más equitativa. De ahí que defendiera una interpretación multilateral de la Doctrina Monroe, rechazara el intervencionismo y fomentara las acciones colectivas. Roosevelt creía en la reciprocidad, por lo que favoreció un quid pro quo diplomático: si los países latinoamericanos mantenían el orden, Estados Unidos cumpliría su promesa de no intervenir en sus asuntos. Esto no quería decir que el mandatario renunciara a defender los intereses estadounidenses en la región por los medios que fueren necesarios. ${ }^{27}$

A pesar de algunas críticas, la mayoría de los gobiernos latinoamericanos vieron a la PBV como el fin del intervencionismo estadounidense y el comienzo de relaciones basadas en la igualdad y el respeto mutuo, de ahí que le apoyaran.

${ }^{26}$ Gilderhus 2000: 75-79.

${ }^{27}$ Marks 1988 y Dallek 1995. 
La PBV funcionó también como una extensión del Nuevo Trato, es decir, de las reformas implementadas por Roosevelt para enfrentar las consecuencias de la crisis económica de la década de 1930. En otras palabras, el acercamiento a América Latina buscaba también ayudar en la recuperación económica estadounidense. El artífice del lado económico de la PBV lo fue el Secretario de Estado Cordell Hull, quien creía que era necesario estimular el comercio internacional para impulsar la recuperación económica, promoviendo acuerdos comerciales recíprocos, que conllevaban la reducción hasta de un 50\% de los aranceles cobrados por Estados Unidos. ${ }^{28}$ Entre 1934 y 1942, Estados Unidos firmó quince de estos acuerdos con naciones latinoamericanas, los cuales fortalecieron las relaciones con América Latina, una región duramente castigada por la crisis. En 1933, las exportaciones estadounidenses hacia América Latina totalizaron $\$ 363$ millones. Seis años más tarde, habían ascendido a \$548 millones. Las importaciones latinoamericanas también se beneficiaron, alcanzaron los $\$ 493$ millones en 1939, un aumento de \$177 millones con relación a $1933 .{ }^{29}$ Estos tratados ayudaron a que, una vez finalizada la Segunda Guerra Mundial y con Europa en ruinas, aumentara el dominio económico estadounidense en América Latina.

La PBV también conllevó una ofensiva ideológica y cultural para contrarrestar la influencia fascista en América Latina. Esta campaña de propaganda incluyó películas, trasmisiones de radio y publicidad. Se buscaba, además, promover la cooperación y vender el American Way of Life, y así adelantar los intereses económicos estadounidenses. Para coordinar este esfuerzo, fue creada la Oficina del Coordinador para Asuntos Interamericanos (OCAI) bajo la dirección de Nelson Rockefeller. La selección del magnate neoyorquino no fue accidental, pues siendo Republicano aportaba un aura bipartita a la oficina. Además, Rockefeller tenía un gran interés en América Latina, promovido, en parte, por sus negocios petroleros en Venezuela. La OCAI contó con el apoyo entusiasta

${ }^{28}$ Gilderhus 2000: 81.

29 Schoultz 1998: 305 y Gilderhus 2000: 79-91. 
de Hollywood en la producción de películas claramente propagandísticas, algunas de ellas no tan exitosas. ${ }^{30}$

Tras la entrada de Estados Unidos a la Segunda Guerra Mundial, la mayoría de los países latinoamericanos cooperaron con sus recursos naturales, y apoyo político y estratégico en el esfuerzo militar estadounidense. ${ }^{31}$ Solo Brasil y México aportaron militarmente. Los brasileños organizaron la Fuerza Expedicionaria Brasileña, que participó activamente en el frente europeo, especialmente en Italia; ${ }^{32}$ mientras que la aportación mexicana estuvo orientada al apoyo aéreo con la creación de la Fuerza Expedicionaria Aérea Mexicana. Los también conocidos como Águilas Aztecas combatieron en el frente del Pacífico, especialmente, en las Filipinas. Ambas fuerzas expedicionarias conllevaron un nivel histórico de cooperación militar con Estados Unidos. Tanto mexicanos como brasileños recibieron entrenamiento, armamento y apoyo logístico de los Estados Unidos. ${ }^{33}$

¿Hasta qué punto la cooperación latinoamericana durante la guerra fue una consecuencia de la PBV? Es indiscutible que la mejora en las relaciones entre Estados Unidos y América Latina que provocó la PBV fue un factor importante en la actitud de los latinoamericanos durante la Segunda Guerra Mundial. Sin embargo, es necesario destacar que otros factores deben ser también tomados en cuenta. Los países latinoamericanos tenían sus propias agendas y preocupaciones, y sabían que solos no serían capaces de enfrentar la amenaza nazi si Alemania salía victoriosa en Europa. En otras palabras, les era conveniente cooperar con la principal fuerza militar e industrial del hemisferio occidental: Estados Unidos. Para algunos países — los más pequeños y económicamente más vulnerables - no cooperar con su principal fuente de inversión y mercado no era una opción. Por último, la cooperación significaba beneficios tangibles para los latinoamericanos: mejores condiciones comerciales, armas, entrenamiento, préstamos, etc.

\footnotetext{
${ }^{30}$ Cramer y Prutsch 2012: 15-44.

${ }^{31}$ Longley 2002: 183.

32 Gilderhus 2000: 99.

${ }^{33}$ Longley 2002: 183.
} 


\section{La cruzada anticomunista}

Los países latinoamericanos esperaban que la PBV sobreviviera al fin de la guerra, pero esto no ocurrió. La alianza de conveniencia que existió entre Estados Unidos y la Unión Soviética durante el conflicto dio a paso a un enfrentamiento ideológico, cultural, científico y económico que se extendió cuatro décadas, y que determinó las relaciones entre estadounidenses y latinoamericanos. En este nuevo contexto internacional, América Latina dejó de ser una prioridad para los Estados Unidos.

Decididos a contener la "amenaza comunista», los Estados Unidos buscaron crear, como en los años treinta, una alianza hemisférica. En la Conferencia Interamericana para el Mantenimiento de la Paz y la Seguridad del Continente celebrada en Río de Janeiro en 1947, los estadounidenses lograron un compromiso latinoamericano a favor de un sistema de seguridad regional. Con la firma del Tratado Interamericano de Asistencia Recíproca, mejor conocido como el Tratado de Río, los países americanos establecieron un compromiso de defensa mutua. Un ataque a cualquier país del hemisferio occidental sería considerado un ataque contra todos. Durante la IX Conferencia Panamericana celebrada en Bogotá en 1948, se acabó de dar forma a la alianza hemisférica con la creación de la Organización de Estados Americanos (OEA). ${ }^{34}$

Para frustración de los países latinoamericanos, la cruzada anticomunista de su poderoso vecino no incluía el tema del desarrollo económico. Preocupado por la situación en Europa - y luego en Asia- el gobierno estadounidense dejó de darle prioridad a América Latina, donde se sentía más seguro de la amenaza comunista. ${ }^{35}$ En otras palabras, como consecuencia de la guerra fría, América Latina se convirtió en una región periférica para los policy makers estadounidenses. De ahí que se desoyeran los pedidos de ayuda y no se desarrollara el equivalente de un Plan Marshall para la región. La ayuda estadounidense que recibieron los países latinoamericanos tras la guerra fue muy reducida. Entre 1945 y 1952, las 20 naciones latinoamericanas recibieron en total menos ayuda

${ }^{34}$ McPherson 2006: 22.

${ }^{35}$ Rabe 2012: 27. 
que Bélgica y Luxemburgo. Durante ese periodo, los estadounidenses insistieron en la apertura al capital estadounidense como el camino al desarrollo para América Latina. ${ }^{36}$

El anticomunismo estadounidense también tuvo repercusiones políticas, ya que marcó el regreso del intervencionismo, justificado por la Doctrina Miller como una herramienta necesaria para enfrentar la «amenaza roja». ${ }^{37}$ Esto vino acompańado de una nueva estrategia, las llamadas acciones encubiertas coordinadas por la Agencia Central de Inteligencia (CIA, por sus siglas en inglés). La CIA formó parte del aparato de inteligencia creado en Estados Unidos para fortalecer la lucha contra el comunismo. El nacionalismo económico y el reformismo latinoamericanos, aun los democráticos, enfrentaron problemas con la visión maniquea estadounidense, pues se les acusó de comunistas. En casos como el derrocamiento del presidente guatemalteco Juan Jacobo Arbenz, las acciones de la CIA tuvieron consecuencias trágicas. ${ }^{38}$ La prioridad de los políticos estadounidense era promover la estabilidad y el statu quo en América Latina. Dictadores como Rafael L. Trujillo y Anastasio Somoza supieron maniobrar en el nuevo contexto para fortalecer su relación con Estados Unidos.

La actitud política y económica de Estados Unidos tras la Segunda Guerra Mundial produjo una profunda decepción entre los líderes latinoamericanos, quienes se sintieron traicionados, pues esperaban que continuara la cooperación forjada durante la PBV y que fuera reconocido el apoyo dado a Estados Unidos durante el conflicto mundial, lo que no ocurrió. A nivel regional, hubo un aumento en el sentimiento antiestadounidense, el cual quedó claramente retratado en el recibimiento que tuvo el vicepresidente Richard M. Nixon durante su gira latinoamericana

${ }^{36}$ Entre 1946 y 1958, América Latina recibió \$2 mil millones en ayuda económica estadounidense; mientras que Europa recibió \$17 mil millones (Rabe 1978).

${ }^{37}$ En un discurso pronunciado en abril de 1950, el entonces Assistant Secretary del Departamento de Estado Edward G. Miller Jr. aclaró que Estados Unidos intervendría para frenar una amenaza comunista contra un país hemisférico (Rabe 2012: 21).

${ }^{38}$ La caída de Arbenz en 1954 llevaría, eventualmente, a una guerra civil de más de 30 ańos y miles de muertos (Immerman 1982; Schlesinger y Kinzer 1982; Gleijeses 1991; y Grandin 2004). 
de $1958 .{ }^{39}$ En Perú, pero sobre todo en Venezuela, Nixon fue recibido por manifestantes que expresaron violentamente su rechazo a lo que este representaba: Estados Unidos. ${ }^{40}$ Alarmada, la administración del presidente Dwight D. Eisenhower buscó, tardíamente, mejorar las relaciones hemisféricas. El fracaso estadounidense en ser un buen vecino en la primera etapa de la guerra fría tuvo consecuencias a largo plazo en las relaciones con América Latina.

\section{La revolución cubana}

Los principales problemas de Estados Unidos en América Latina a finales de la década de 1950 estuvieron localizados en el Caribe. El estallido en Cuba de una rebelión popular contra un dictador y aliado anticomunista de los estadounidenses terminó convirtiéndose en la peor derrota de Estados Unidos de la guerra fría. Bajo el liderato de un joven abogado llamado Fidel Castro, los cubanos pusieron en jaque la dictadura de Fulgencio Batista. Incapaces de encontrar una alternativa viable a un aliado que se había convertido en un problema, las autoridades estadounidenses no pudieron frenar el avance de las fuerzas revolucionarias, que entraron victoriosas a La Habana en enero de 1959, dando comienzo a la Revolución Cubana. ${ }^{41}$

Incapaces de entender al nacionalismo cubano, los funcionarios de la administración Eisenhower no se percataron de que la caída de Batista había marcado el comienzo de una nueva era la historia de la isla (y de sus relaciones con los Estados Unidos). Erróneamente, creyeron que las relaciones con el nuevo gobierno cubano podrían continuar como en el pasado. No advirtieron que para los líderes revolucionarios cubanos era prioritario reafirmar la soberanía cubana frente al control económico e influencia política de Estados Unidos, y que ello les hacía tremendamente sensibles a cualquier forma de crítica o intervención estadounidense en los asuntos internos de Cuba. ${ }^{42}$

\footnotetext{
${ }^{39}$ McPherson 2003: 9-37.

40 Zahnizer y Weis 1989.

${ }^{41}$ Benjamin 1990 y Paterson 1994.

42 Perez 1999: 393-395.
} 
Cubanos y estadounidenses estaban separados por sus respectivas interpretaciones históricas del papel jugado por Estados Unidos en la historia de Cuba. Mientras los funcionarios de la administración Eisenhower creían que Cuba estaba en deuda con los Estados Unidos por haberles liberado del yugo español en 1898, los cubanos estaban convencidos de que la intervención estadounidense en su guerra con España había privado a la isla de ser verdaderamente libre. Los revolucionarios cubanos tenían muy claro el significado de la enmienda Platt y de las intervenciones directas estadounidenses en 1906, 1912 y 1917, así como también el papel que jugó Estados Unidos durante la fallida revolución de 1933. ${ }^{43}$ De ahí su interés en reafirmar su soberanía frente a un país que, además, tenía una inversión directa en la isla que totalizaba $\$ 1$ mil millones. Los estadounidenses, además, controlaban el $90 \%$ de las minas, el $40 \%$ de la industria azucarera y el $50 \%$ de la tierra cultivable. ${ }^{44}$

Las claras diferencias entre cubanos y estadounidenses llevaron a un rompimiento y al acercamiento de Cuba a la Unión Soviética, que culminó con la transformación de la isla en un enemigo directo de Estados Unidos. La revolución pudo sobrevivir gracias al apoyo soviético, convirtiéndose en una amenaza para la hegemonía estadounidense en el hemisferio occidental. ${ }^{45}$

La consolidación de la Revolución Cubana puede ser considerada la primera gran derrota estadounidense en América Latina. Esta se convirtió en un modelo de resistencia antiimperialista y de reafirmación nacional basado en la lucha armada (foco guerrillero) como medio hacia el cambio sociopolítico. Cuba también se convirtió en un modelo de desarrollo económico alterno. Con el apoyo económico, militar y científico soviético, los cubanos adoptaron el socialismo (la economía planificada) como el vehículo hacia el desarrollo y el fin de la dependencia económica. Los revolucionarios pusieron en práctica una reforma agraria, expropiaron recursos naturales y nacionalizaron empresas extranjeras, sobre todo,

\footnotetext{
43 Pérez 1999: 393-395. Los revolucionarios cubanos tampoco olvidaban el apoyo militar y económico estadounidense a la dictadura de Batista.

${ }^{44}$ Paterson 1994 y Benjamin 1990.

45 McPherson 2006: 49.
} 
estadounidenses. La Revolución también conllevó un modelo de organización política y social alterna con programas de redistribución de la riqueza, de alfabetización, culturales y de salud social. Todo ello unido al carisma y popularidad de Fidel Castro impactó a diversos sectores de la sociedad latinoamericana, especialmente, a una generación de jóvenes. La Revolución validó la violencia como un medio para lograr cambios sociales, económicos y políticos, y ayudó en la radicalización de sectores de la izquierda latinoamericana, lo que terminará polarizando a América Latina con resultados trágicos. ${ }^{46}$

Como consecuencia de la Revolución Cubana, Latinoamérica se convirtió en protagonista de la guerra fría. Antes de la Revolución, América Latina había jugado un papel menor en la confrontación soviético-estadounidense. Castro y sus barbudos alteraron el balance internacional, provocaron un recrudecimiento de la guerra fría y casi desatan una guerra nuclear durante la crisis de los misiles. Es necesario subrayar que la Revolución no alteró la posición hegemónica de Estados Unidos en el hemisferio occidental, pero sí provocó una revisión de las estrategias y prioridades de los líderes estadounidenses. América Latina pasó a ser una prioridad para los Estados Unidos, lo que no ocurría desde la PBV. ${ }^{47}$

En la década de 1960, el objetivo de los estadounidenses fue evitar la expansión hemisférica del virus cubano a toda costa. Los estadounidenses procedieron a aislar a Cuba expulsándole de la OEA y decretando un bloqueo económico, social y cultural contra la isla. Además, procedieron a ayudar militarmente a los gobiernos latinoamericanos para que fuesen capaces de enfrentar a quienes buscaran repetir el modelo guerrillero cubano. Los soldados latinoamericanos fueron asesorados por Boinas Verdes en técnicas de contrainsurgencia y los oficiales aprendieron métodos de interrogatorio y tortura en la Escuela de las Américas. ${ }^{48}$

\footnotetext{
${ }^{46}$ Westad 2007: 170-180.

${ }^{47}$ McPherson 2006: 48.

${ }^{48}$ Rabe 2012: 85-113.
} 
El gobierno estadounidense no se limitó al apoyo militar, pues buscó a ser nuevamente un buen vecino a través de un programa de ayuda económica conocido como la Alianza para el Progreso (AP). Propuesta por el presidente John F. Kennedy en 1961, la AP buscaba acabar con las condiciones socioeconómicas que propiciaban las revoluciones en América Latina: atraso, pobreza, desigualdad, etc. Para la administración estadounidense, promover el progreso y la prosperidad se convirtió en una prioridad para combatir el comunismo en América Latina. Kennedy propuso un plan de diez años para acelerar el desarrollo económico, y promover el desarrollo social y la democracia en América Latina. ${ }^{49}$ Los líderes estadounidenses creían que, al promover la diversificación del comercio, la industrialización, la reforma agraria y la alfabetización, frenarían la expansión del virus cubano. ${ }^{50}$

La AP conllevó un aumento significativo en la ayuda económica estadounidense para América Latina. Entre 1962 y 1967, la región recibió $\$ 1.4$ millones anuales en ayuda económica. En un periodo de diez años, la ayuda total llegó a los \$22.3 mil millones. ¿Fue esto suficiente para cumplir con sus objetivos? La respuesta es no, pues, aunque hubo crecimiento económico en la región (2.4 promedio en la década de 1960), la ayuda económica jugó un papel menor en este proceso..$^{51}$ Además, los logros sociales de la AP fueron limitados, tal vez porque eran muy ambiciosos. No se acabó con el analfabetismo ni con la pobreza y, por ende, con sus consecuencias sociopolíticas.

¿Por qué fracasó la AP? Por varias razones. En primer lugar, porque los niveles de ayuda, aunque impresionantes a primera vista, fueron insuficientes para un programa tan ambicioso. En segundo lugar, los norteamericanos pensaban que su programa recibiría apoyo local y no fue así por la oposición de las clases media y alta latinoamericanas. En tercer y último lugar, por la debilidad de las fuerzas reformistas y democráticas

\footnotetext{
${ }^{49}$ Field 2014.

50 Smith 1999: 147-152.

${ }^{51}$ De acuerdo con Peter H. Smith, este crecimiento de debió a tres factores: la aplicación exitosa de estrategias de sustitución de importaciones, la demanda internacional por materias primas y la inversión privada (Smith 1999: 152).
} 
locales. La falta de interlocutores válidos para la AP fue consecuencia, en parte, de la política estadounidense en la primera etapa de la guerra fría que combatió como comunismo los intentos reformistas en la región. ${ }^{52}$

La AP también fracasó en su objetivo de promover la democracia. Solo entre 1962 y 1963 hubo seis golpes de estado en América Latina: Argentina (1962), Perú (1962), Guatemala (1963), Ecuador (1963), República Dominicana (1963) y Honduras (1963). A estos habría que añadir el golpe de estado que acabó con el gobierno nacionalista de Joaó Goulart en Brasil en 1964. Este golpe militar contó con el apoyo estadounidense y dio paso a una dictadura que se extendió 21 años en el país más importante de América Latina. Para 1968, había dictaduras militares en Perú, Argentina, Brasil, Paraguay, casi toda América Central, Bolivia y Ecuador. ${ }^{53}$

Se podría alegar que el punto culminante de este periodo fue la invasión de la República Dominicana. Tras ańos de controlar a los dominicanos con puño de hierro y el apoyo del gobierno estadounidense, Rafael L. Trujillo fue asesinado en 1961. Su muerte, como era de esperar, abrió un periodo de inestabilidad política, pero con un final feliz: la celebración de las primeras elecciones democráticas en décadas. Los dominicanos eligieron presidente al escritor Juan Bosch, quien llegó al poder con un programa de reformas socioeconómicas que no fue bienvenido por todos sus conciudadanos. Tras solo siete meses en la presidencia, Bosch fue derrocado en setiembre de 1963 y su gobierno fue sustituido por un triunvirato dominado por trujillistas. Frustrados por el regreso del trujillismo sin Trujillo, las masas dominicanas se rebelaron en 1965, reclamando la restauración de Bosch en la presidencia. La amenaza de una guerra civil y, principalmente, el miedo a que la República Dominicana se convirtiera en otra Cuba llevaron a la administración Jonhson — con el apoyo de la OEA - a invadir la nación caribeña. Tras la invasión, República Dominicana pasó a ser gobernada por Joaquín Balaguer, un extrujillista, quien mantuvo un gobierno represivo por doce años. ${ }^{54}$

\footnotetext{
52 Smith 1999: 152-153 y Offiler 2010.

53 Smith 1999: 154-157.

${ }^{54}$ Smith 1994: 125-127.
} 
En el caso dominicano, las intenciones estadounidenses de ser un buen vecino chocaron con las realidades geopolíticas y los determinismos ideológicos. Expuestos a decidir entre fomentar democracia y reformas socioeconómicas, y frenar una amenaza comunista (real o imaginada), los policy makers estadounidenses optaron por lo segunda y recurrieron a su vieja arma: el intervencionismo militar. Muchos latinoamericanos vieron la invasión de la República Dominicana como otro ejemplo del abuso del poder estadounidense en América Latina, es decir, como la prueba de la incapacidad de Estados Unidos para ser un buen vecino.

\section{La década perdida}

La década de 1970 fueron una década controversial en la historia de Estados Unidos y América Latina, como también en sus relaciones internacionales. Los estadounidenses vieron a un presidente renunciar y al país perder una guerra. Los latinoamericanos fueron víctimas de la polarización política e ideológica, de crisis económicas, del terrorismo, de las guerras sucias, etc. Varios países latinoamericanos se vieron atrapados en la lucha ideológica y estratégica entre la Unión Soviética y los Estados Unidos, con resultados funestos. Todo ello frenó las posibilidades de cambios socioeconómicos pacíficos en la región.

Tal vez el caso emblemático sea el de Chile, donde un presidente socialista y democráticamente electo, fue derrocado brutalmente por las fuerzas armadas. Salvador Allende llegó al Palacio de la Moneda con sólo el 36\% del voto, lo que no evitó que pusiera en marcha su programa socialista. ${ }^{55}$ Para el gobierno estadounidense - liderado por Richard M. Nixon con la asesoría de Henry Kissinger - la victoria de Allende en 1970 constituyó una amenaza. Chile era un país muy importante para Estados Unidos, ya que durante la AP recibió más de \$1 mil millones en ayuda estadounidense. Además de poseer las enormes reservas de cobre, en Chile había inversiones estadounidenses por un valor de \$961 millones.

Los líderes estadounidenses estaban atentos a la amenaza de una victoria izquierdista en Chile mucho antes de 1970. De ahí que apoyaran

${ }^{55}$ Harmer 2011: 49-56. 
económicamente a candidatos menos radicales que Allende. Sin embargo, no pudieron evitar que este se convirtiera en el presidente democráticamente electo de Chile. Allende disfrutaba de una legitimidad que carecían otros líderes regionales, pues no había llegado al poder a través de un golpe de estado o una revolución. Contrario a Castro, Allende era un demócrata y eso le hacía aún más peligroso para los estadounidenses en el contexto de la guerra fría, pues legitimaba al socialismo como una opción política. ${ }^{56}$

Las acciones de Allende confirmaron los temores estadounidenses. El nuevo gobierno chileno llevó a cabo una política exterior independiente, que retó a Estados Unidos al establecer relaciones diplomáticas con países comunistas como Cuba, Vietnam del Norte y Corea del Norte. A nivel doméstico, Allende nacionalizó el cobre, promulgó una reforma agraria y llevó a cabo importantes reformas, educativas, sanitarias y sociales. El rechazo de la Iglesia Católica, la clase media, la burguesía y la clase propietaria chilenas provocó una gran polarización social, una verdadera guerra de clases. ${ }^{57}$

Temerosos del posible renacer del virus cubano, Nixon y su Secretario de Estado Henry Kissinger, le declararon la guerra a Allende. El gobierno estadounidense usó todo su poder económico y político para desestabilizar a Chile y destruir a su presidente. Ello, unido a los errores de Allende y a la polarización de la sociedad chilena, llevaron al fin de la democracia chilena. El 11 de setiembre de 1973, las fuerzas armadas derrocaron a Allende en un violento golpe de estado que le costó la vida al líder socialista. Chile pasó a ser gobernado por una junta militar que desató una salvaje campaña de represión contra los sectores izquierdistas y progresistas de la sociedad chilena bajo la mirada despreocupada de la administración Nixon. ${ }^{58}$

Los chilenos no fueron las únicas víctimas del terrorismo de Estado. En las décadas de 1970 y 1980, un grupo de países sudamericanos experimentaron una violenta represión por parte del Estado. Durante las

\footnotetext{
${ }^{56}$ Haslam 2005: 54-60 y Harmer 2011: 56-72.

57 Harmer 2011: 79-98.

58 Westad 2007, 201 y Harmer 2011: 220-254.
} 
llamadas «guerras sucias», miles de personas fueron violadas, torturadas, asesinadas y/o desaparecidas por su vinculación — real o imaginada — con partidos o grupos de izquierda. La represión formó parte de una campaña de terrorismo de Estado conocida como Operación Cóndor, en la que participaron Brasil, Argentina, Chile, Bolivia, Paraguay, Uruguay, Perú y Ecuador. Las fuerzas de inteligencia de estos países — algunos de ellos enemigos históricos - desarrollaron una colaboración sin precedentes en la destrucción de lo que consideraban un enemigo común.

Según Joan Patrice McSherry, la Operación Cóndor fue el resultado de la lucha de clases que vivió América Latina en la década de 1970. McSherry argumenta que los militares latinoamericanos derrocaron gobiernos civiles «cuando la orientación de clase del Estado se encontraba a punto de cambiar o se encontraba en el proceso de cambio para trasladar el poder estatal a los sectores sociales no elitistas». ${ }^{59} \mathrm{La}$ Operación Cóndor fue posible gracias al respaldo de las élites locales y el soporte técnico del gobierno de Estados Unidos. La alianza entre las élites y los militares buscaba retener el control del Estado, amenazado por quienes demandaban cambios políticos y socioeconómico. ${ }^{60} \mathrm{El}$ apoyo del gobierno estadounidense fue el resultado de su doctrina anticomunista de seguridad nacional. Los dirigentes políticos estadounidenses querían mantener su hegemonía hemisférica mediante gobiernos que les fueran favorables y defendieran el capitalismo, por lo que apoyaron a las élites y los militares latinoamericanos. Nuevamente, se impusieron las realidades geopolíticas y los determinismos ideológicos.

\section{La muerte prematura de la Doctrina Monroe}

Las elecciones presidenciales estadounidense de 1976 se dieron en un contexto muy particular. La nación estadounidense seguía bajo los efectos de la derrota en Vietnam y del escándalo de Watergate. ${ }^{61}$ Las revelaciones del Comité Church sobre la participación de las agencias de inteligencia

\footnotetext{
${ }^{59}$ McSherry 2009: 39.

${ }^{60}$ Ib.: 60 .

${ }^{61}$ Longley 2002: 271.
} 
estadounidenses en acciones encubiertas hicieron que se conocieran los crímenes cometidos por el gobierno de Estados Unidos en Asia, África y América Latina. ${ }^{62}$

El Partido Demócrata nominó a la presidencia a un político sureño desvinculado de los círculos de poder en Washington llamado James Carter, quien ganó las elecciones por un estrecho margen. Carter prometió en su campaña la renovación moral de la nación estadounidense. Bajo la influencia de la Comisión Linowitz, Carter buscó reorientar la política exterior estadounidense. ${ }^{63} \mathrm{En}$ su discurso ante los graduandos de la Universidad de Notre Dame en mayo de 1977, Carter dejó claro cuáles serían las prioridades de su política exterior. El recién inaugurado presidente condenó la idea de que Estados Unidos debía apoyar regímenes represivos como parte de la estrategia para frenar el comunismo porque iba en contra de los valores de la nación estadounidense. Menos preocupado por la amenaza soviética, Carter buscó alejarse de las prácticas de sus predecesores convirtiendo a los derechos humanos en uno de los ejes principales de su política exterior. ${ }^{64}$ Para el presidente, los Estados Unidos debían usar su poderío para presionar a otros países en materia de derechos humanos. ${ }^{65}$

${ }^{62}$ Dirigido por el senador Frank Church, este comité produjo dos informes titulados Covert Action in Chile y Alleged Assassination Plots Involving Foreign Leaders (McPherson 2006: 78-79).

${ }^{63}$ La Commission on United States-Latin American Relations estaba compuesta por «an independent, bipartisan group of private citizens from different sectors of U.S. society». Dirigida por Sol Linowitz y con el apoyo económico de las Fundaciones Ford, Rockefeller y Clark, la comisión concluyó que los objetivos y presunciones de la política norteamericana para América Latina eran no solo inapropiados, sino también irrelevantes en el contexto de mediados de la década de 1970. En su informe final, la comisión sugirió, entre cosas, el fin del embargo a Cuba, la devolución del Canal de Panamá, no más operaciones encubiertas o intervenciones, el fin de la diplomacia del dólar y de la ayuda militar, y que la ayuda económica estadounidense se concentrara en combatir la pobreza en América Latina (Pastor 1992: 45-47).

${ }^{64}$ Smith 1994: 139.

${ }^{65} \mathrm{La}$ administración Carter les retiró la ayuda económica a los gobiernos militares de Argentina y Uruguay, entre otros. Además, creó una Oficina de Derechos Humanos adscrita al Departamento de Estado (Schmidli 2011 y 2012). 
La administración Carter dio mucha importancia a América Latina. Con el objetivo de mejorar las relaciones con sus vecinos meridionales, se hizo un esfuerzo por no pensar o actuar en términos de la Doctrina Monroe. En otras palabras, se rechazó el monroísmo como base de la política exterior hacia América Latina. Zbiniew Brzezinsky, asesor de Seguridad Nacional de Carter, tenía claro que en América Latina la Doctrina Monroe era vista como una herramienta del imperialismo estadounidense. Los estadounidenses podrían estar orgullosos de dicha doctrina, pero era claro que los latinoamericanos no. ${ }^{66}$

Carter convirtió la defensa de los derechos humanos en la piedra angular de su política exterior. ${ }^{67}$ Bajo su gobierno, los países eran medidos en términos de su respeto a los derechos civiles, no en términos de su posición geográfica o apoyo contra el comunismo. Esta política complicó las relaciones con importantes aliados latinoamericanos como Nicaragua, Argentina, Paraguay, Chile y Brasil, claros violadores de los derechos humanos. ${ }^{68}$

El mayor éxito de Carter en América Latina fue el Tratado CarterTorrijos, definiendo una fecha para la devolución del Canal a los panameños. Carter llegó a la Casa Blanca convencido de que el control de un territorio como el Canal que dividía a un país en dos era un anacronismo inmoral que debía ser resuelto. Resolver el tema del Canal era visto como una muestra de las intenciones de su administración hacia América Latina. Sin embargo, este fue un tema políticamente muy costoso para Carter. No todos los estadounidenses apoyaban la devolución del Canal, ya que le veían como un símbolo del ingenio, poderío y voluntad de Estados Unidos. Para otros, el Canal era un símbolo de la hegemonía hemisférica estadounidense, por ende, su devolución sería vista como una muestra de debilidad. El tema del Canal dio a los Republicanos una oportunidad para recuperarse políticamente tras los escándalos de

${ }^{66}$ Longley 2002: 272-274.

${ }^{67}$ Es necesario señalar que Carter no enfatizó el tema de los derechos humanos en las relaciones con países no hemisféricos que eran considerados claves para Estados Unidos (Smith 1994: 160).

${ }^{68}$ Smith 1994: 140-141. 
la administración Nixon. Ronald Reagan, exgobernador de California y potencial candidato presidencial Republicano para las elecciones de 1980, atacó a Carter acusándole de débil, representando la devolución del Canal como un acto de traición. A pesar de la fuerte oposición, Carter logró la ratificación senatorial del Tratado, pero el costo político fue muy alto, pues dio a sus enemigos argumentos en su contra. ${ }^{69}$

Carter también buscó mejorar las relaciones con Cuba, pues consideraba contradictorio que Estados Unidos tuviera relaciones diplomáticas con otros países comunistas, pero mantuviese aislado a su vecino caribeño. Tras negociaciones secretas entre delegaciones cubanas y estadounidenses, se llegó a un acuerdo para la apertura de oficinas de intereses en Washington y La Habana. Este era un importante primer paso hacia un eventual restablecimiento de las relaciones diplomáticas. Sin embargo, el acercamiento a Cuba fracasó por varios factores. En primer lugar, por un recrudecimiento de la guerra fría como consecuencia de la presencia de tropas cubanas y soviéticas en África. En segundo lugar, por un aumento de la presencia militar soviética en Cuba. En tercer lugar, por la presión política de los Republicanos y del exilio cubano. En cuarto lugar, por el éxodo de Mariel en $1980 .^{70}$

A su vez, los problemas en Centroamérica complicaron seriamente las intenciones de Carter. En Nicaragua, un viejo amigo de Estados Unidos, el dictador Anastasio Somoza Debayle enfrentó una rebelión popular. Cansados de casi cuarenta años de la dictadura de la familia Somoza, los nicaragüenses se rebelaron bajo el liderato del Frente Sandinista de Liberación Nacional. Las violaciones de los derechos humanos por el gobierno de Somoza captaron la atención de Carter, provocando críticas, especialmente, de los amigos del dictador en el Congreso. ${ }^{71}$ En febrero de 1979, se le cortó la ayuda económica al régimen nicaragüense, lo que llevó a los enemigos de Carter a acusarle de abandonar a un amigo y de abrir las puertas a una nueva Cuba. Tras la caída de Somoza en julio de

\footnotetext{
${ }^{69}$ Pastor 1992: 45-50 y Zaretsky 2011.

${ }^{70}$ Longley 2002: 276-278.

${ }^{71}$ LaFeber 1983: 210.
} 
1979, Carter buscó un acercamiento con el nuevo gobierno dominado por los sandinistas, provocando que se le acusara de débil nuevamente.

La invasión soviética de Afganistán y la crisis de los rehenes en Irán provocaron un endurecimiento de la política exterior de Carter y complicaron su situación política previa a las elecciones presidenciales de noviembre de 1980. El acercamiento de Nicaragua a Cuba y la Unión Soviética, unida a la ayuda sandinista a los guerrilleros salvadoreños, llevaron a Carter a adoptar una política más dura.

El Salvador fue otro dolor de cabeza para Carter. Controlado férreamente por una oligarquía de catorce familias y con una tradición histórica de dictaduras y represión, El Salvador era en los años 1970 un volcán a punto explotar. En 1979, un golpe de estado acabó con el gobierno del general Carlos Humberto Romero, abriendo un periodo de guerra civil que se extendió por doce años. Bajo el liderato del Frente Farabundo Martí para la Liberación Nacional (FMLN), un grupo guerrillero de orientación izquierdista, los salvadoreños se rebelaron contra el terrorismo de Estado, la desigualdad, la pobreza y la falta de democracia. ${ }^{72} \mathrm{La}$ oligarquía y el Ejército salvadoreño reaccionaron con una brutal represión por medio de escuadrones de la muerte, paramilitares, desapariciones, etc. En marzo de 1980, fue asesinado el arzobispo de El Salvador, monseñor Óscar Arnulfo Romero Padilla, duro crítico del gobierno. ${ }^{73}$ En diciembre de ese año, cuatro monjas estadounidenses fueron violadas y asesinadas por soldados salvadoreños. Todo ello complicó la ya difícil situación de la administración Carter. Ante el flujo de armas a la guerrilla procedente de Nicaragua y Cuba, Carter autorizó a la CIA a dar ayuda a los grupos antisandinistas, la famosa Contra. ${ }^{74}$ En el caso de la administración Carter, vemos como nuevamente la guerra fría -y los factores de política interna estadounidenses- se impusieron a las buenas intenciones.

\footnotetext{
${ }^{72}$ Longley 2002: 282-285.

${ }^{73}$ LaFeber 1983: 242-256.

${ }^{74}$ Pastor 1992: 58-59.
} 


\section{EL REGRESO DE LA DOCTRINA MONROE}

Debilitado por la mala situación económica y la crisis de los rehenes en Irán, Carter se presentó a las elecciones presidenciales de 1980 en desventaja frente a su oponente, el exgobernador de California Ronald Reagan. Este llevó a cabo una exitosa campaña electoral basada en un fuerte discurso nacionalista y en la representación de Carter como un líder débil y antiestadounidense. Carter sufrió una derrota aplastante, ya que solo ganó dos estados y el $41 \%$ del voto popular.

Reagan desarrolló una política exterior muy agresiva, caracterizada por un feroz anticomunismo. El nuevo mandatario buscaba reafirmar el poder, confianza y la autoridad internacional de los Estados Unidos afectados por la derrota sufrida en Vietnam. Para Reagan, el comunismo era el mal del mundo moderno y la URSS, el «imperio del mal». Los Estados Unidos tenían que liderar la lucha en su contra y frenar su expansión, especialmente, en América Latina. Reagan se veía a sí mismo como heredero de James Monroe, enfrentando conspiraciones comunistas en el hemisferio occidental. ${ }^{75}$

El anticomunismo de Reagan le llevó a oponerse a cualquier tipo de revolución social en América Latina. Una de sus principales preocupaciones fue la revolución iniciada en Nicaragua tras la derrota de la dictadura de Somoza. Acabar con la revolución nicaragüense se convirtió en una prioridad de su gobierno. La encargada de tal labor fue la CIA, que llevó a cabo una guerra encubierta contra el gobierno sandinista. En 1981, Reagan aprobó la asignación de \$19 millones de dólares para que la CIA entrenara y armara a un grupo de guerrilleros de derecha, los Contras, con el objetivo de derrocar al gobierno nicaragüense. Tomó más de una década, pero al final la estrategia norteamericana tuvo éxito. En 1990, la candidata conservadora Violeta Chamorro ganó las elecciones presidenciales nicaragüenses, lo que marcó el principio del fin de la revolución sandinista. ${ }^{76}$

75 McPherson 2006: 89-92.

${ }^{76}$ Rabe 2012: 159-164. 
Reagan también enfrentó los problemas relacionados a la guerra civil en El Salvador. Como en el caso de Nicaragua, Reagan identificó la guerra civil salvadoreña como otra amenaza del comunismo internacional y apoyó económica y militarmente al gobierno salvadoreño, a pesar de sus claras violaciones de los derechos humanos. La ayuda militar norteamericana hacia El Salvador aumentó de \$6 millones en 1980 a \$82 millones en 1982. Para 1983, los escuadrones de la muerte salvadoreños, promovidos por las fuerzas armadas del país, habían asesinado y torturado a miles de opositores al régimen. En 1984, hubo elecciones en El Salvador y resultó electo presidente José Napoleón Duarte, un líder de centro. No obstante, ello no frenó una guerra que ya había costado la vida de por los menos 53,000 salvadoreños. ${ }^{77}$

El peor escándalo de la administración Reagan estuvo relacionado con su campaña anticomunista en América Central. En 1984, el Congreso aprobó una medida que buscaba frenar la guerra encubierta de la administración Reagan en América Central. La Enmienda Boland prohibía que el gobierno federal apoyara directa o indirectamente actividades paramilitares en Nicaragua. De esta forma, el Congreso le negó fondos a la guerra encubierta de la CIA contra los sandinistas, obligando a funcionarios del Consejo de Seguridad Nacional a organizar una operación clandestina que recaudó, entre 1984 y 1987, \$32 millones para apoyar a los Contras. Esta acción constituía una franca violación a la constitución de los Estados Unidos, que, al hacerse pública, generó una gran controversia. ${ }^{78}$

A finales de 1986, un periódico libanés reveló que funcionarios estadounidenses le había vendido misiles antitanques a Irán en violación al embargo en la venta de armas decretado por el gobierno de Carter. En 1987, un comité presidencial creado para investigar este escándalo adjudicó la responsabilidad por la venta de los misiles a Donald Regan, jefe de personal de la Casa Blanca, quien tuvo que renunciar a su puesto. ${ }^{79}$

77 Rabe 2012: 169-172. Según Doug Stokes, entre 1979 y 1992 murieron 80,000 salvadoreńos víctimas de la guerra civil (Stokes 2003: 79).

78 Smith 1994: 200-201 y McPherson 2006: 101-106.

${ }^{79}$ LaFeber 1994: 727-729. 
La renuncia de Regan no acabó con el escándalo, pues pronto se supo que el teniente coronel Oliver North, miembro del Consejo de Seguridad Nacional, había secretamente desviado las ganancias de la venta de armas a Irán hacia los Contras. En mayo de 1987, un comité legislativo inició una investigación televisada del escándalo. Los estadounidenses pudieron ver en vivo el testimonio de North vestido en su uniforme militar, ufanándose de su patriotismo. También testificó el almirante John Poindexter, asesor de Seguridad Nacional del Presidente, quien alegó haber mantenido la operación fuera del conocimiento de Reagan. ${ }^{80}$

En 1989, North fue juzgado y encontrado culpable de obstruir una investigación legislativa, y de destruir y falsificar documentos gubernamentales. Sin embargo, su condena fue más tarde revocada gracias a un tecnicismo legal. El Caso Irán-Contras no llegó al nivel de Watergate, pero dejó claro el estilo abusivo e intervencionista de la política exterior de Reagan hacia América Latina. Definitivamente, en los años 1980, Estados Unidos no fue un buen vecino.

\section{EL FIN DE LA GUERRA FRÍA}

A pesar de los escándalos, los Republicanos mantuvieron el control de la Casa Blanca con la elección, en 1988, de George H. W. Bush a la presidencia. Bush era un político con una amplia experiencia en asuntos internacionales, pues, entre otras cosas, había sido vicepresidente bajo Reagan, director de la CIA y embajador de los Estados Unidos ante las Naciones Unidas.

A Bush le tocó ser testigo del fin de la guerra fría. En los últimos años de la década de 1980, los países de la Europa del este, aliados forzosos de la Unión Soviética, fueron uno a uno declarando su independencia. La caída del muro de Berlín en noviembre de 1989 marcó el inicio de una nueva etapa en la historia europea. La propia Unión Soviética cayó víctima de los nuevos tiempos. En 1991, Lituania, Letonia y Estonia se declararon independientes. Poco a poco, otras repúblicas pertenecientes

${ }^{80}$ Smith 1994: 205-206. El comité legislativo no encontró pruebas de que el presidente hubiese participado del esquema ilegal para allegar fondos a los Contras. 
a la Unión Soviética fueron declarando su independencia, hasta que en 1991 desapareció el gobierno soviético y surgió la Federación Rusa bajo el liderato de Boris Yeltsin. La desaparición de la Unión Soviética marcó el fin de la guerra fría.

El desvanecimiento de la «amenaza soviética» permitió a Bush dar una orientación pragmática a la política exterior estadounidense, dejando atrás el determinismo ideológico que caracterizó el periodo de Reagan. América Latina jugó un papel importante en este proceso. Durante la gestión de Bush se sentaron las bases para una relación hemisférica coherente con el nuevo orden mundial, más abierta y basada en la promoción de reglas democráticas, el impulso de reformas económicas de corte liberal, con la defensa del libre mercado y comercio como centro. Estas reformas buscaban reducir el estatismo y el proteccionismo, y fomentar las inversiones privadas, obviamente, de capital estadounidense. ${ }^{81}$

En junio de 1990, Bush lanzó la Iniciativa Empresarial para las Américas (IEA), una propuesta de integración económica y comercial con los países latinoamericanos y caribeños, cuyo principal objetivo era formar una nueva relación hemisférica basada en la asociación económica que promoviese el intercambio comercial y la inversión. A través de las reformas de mercado se esperaba que las economías latinoamericanas crecieran, generando prosperidad y estabilidad política. La IEA consistía en tres propuestas: fomentar la competitividad latinoamericana para atraer inversión extranjera, la creación —a largo plazo — de una zona de libre comercio hemisférica y la reducción negociada de la deuda latinoamericana. ${ }^{82}$

La IEA fue recibida positivamente por varios líderes latinoamericanos, quienes no escatimaron en las hipérboles. Por ejemplo, el entonces presidente de Venezuela Carlos Andrés Pérez las describió como «La propuesta más avanzada de Estados Unidos para América Latina. Es revolucionaria, un hecho histórico». Para el presidente de Argentina, Carlos Menem, la IEA era «El momento más brillante de nuestras relaciones con

${ }^{81}$ Pastor 1992: 83-103.

${ }^{82}$ Smith 1999: 249, 305-306. 
Estados Unidos». Según Luis Lacalle, presidente de Uruguay, la IEA era una oferta que los latinoamericanos no podían rechazar. En palabras de Lacalle, «Cuando, tras años de quejarnos de desinterés, el hombre más importante del mundo nos tiende la mano, creo que debemos tomarla, y también el brazo, y el codo, y el hombro». ${ }^{83}$

La propuesta de Bush no se materializó por la oposición de diversos sectores de la sociedad estadounidense (sindicatos, ambientalistas, agricultores). Incapaz de alcanzar un acuerdo de libre comercio hemisférico, el gobierno optó por los tratados bilaterales. En 1987, los Estados Unidos y Canadá firmaron un acuerdo de libre comercio que se amplió con la entrada de México en diciembre de 1992. Para los críticos del Tratado de Libre Comercio de América del Norte (TLCAN), la inclusión de México en la zona de libre comercio provocaría la pérdida de miles de empleos. Por el contrario, sus defensores alegaban que la apertura del mercado mexicano provocaría la creación de empleos en los Estados Unidos. Tras un intenso debate público, el Senado ratificó el tratado en $1993 .^{84} \mathrm{El}$ TLCAN creó un bloque comercial de 370 millones de personas, sólo superado en tamaño por la Unión Europea, que generó un aumento sustancial en el comercio entre las tres naciones norteamericanas. ${ }^{85}$

Bush mantuvo muchas de las políticas de su predecesor, entre ellas, la llamada guerra contra las drogas. El gobierno norteamericano buscaba frenar el tráfico de drogas, especialmente, de la cocaína procedente de América del Sur, brindando ayuda militar a los gobiernos de los países productores de coca. El problema de las drogas era uno muy serio, pues para 1990 los norteamericanos gastaban $\$ 100$ mil millones anuales en su consumo. Bush respondió a los reclamos populares contra el problema de las drogas lanzando un programa antidroga de $\$ 8$ mil millones. ${ }^{86}$

Este análisis de lo que significó la administración Bush para América Latina quedaría incompleto si no mencionamos que a mediados de

${ }^{83}$ Todas las citas están en Raymont 2005: 319-320.

${ }^{84}$ Palmer 2006: 24-25.

${ }^{85}$ McPherson 2006: 113-114.

${ }^{86}$ McPherson 2006: 124-126. Sobre el impacto en América Latina de la guerra contra las drogas, se puede consultar a Youngers y Rosin 2005. 
diciembre de 1989 Bush ordenó la invasión de Panamá para sacar del poder al general Manuel Antonio Noriega. El general Noriega era un viejo amigo de los Estados Unidos. Como tal, había colaborado con la CIA en la década de 1980 hasta convertirse en lo que el desaparecido politólogo estadounidense Chalmers Johnson identificó, usando terminología de la CIA, como un blowback, es decir, una consecuencia imprevista de la política exterior estadounidense. ${ }^{87} \mathrm{El}$ dictador pasó de amigo a enemigo, especialmente, por sus vínculos con el narcotráfico. Los esfuerzos de la administración Bush para sacar a Noriega del poder culminaron con la invasión de diciembre de 1989. No se tiene claro cuántos panameńos murieron durante la invasión que llevó a la captura y extradición de Noriega. ${ }^{88}$

No queda tampoco del todo claro por qué un presidente que dio pasos concretos para mejorar las relaciones con América Latina fue quien ordenó una de las últimas invasiones estadounidenses de un país latinoamericano. La justificación oficial fue la protección de las vidas de soldados estadounidenses, la seguridad del Canal, los vínculos de Noriega con el narcotráfico y la promoción de la democracia. Lo que resulta indiscutible es que la invasión conllevó un uso innecesario y desproporcionado de la fuerza, que confirmó una vez más lo difícil que le resulta a una potencia ser un buen vecino.

A pesar de la invasión de Panamá, es necesario concluir que el acercamiento «rooseveltiano» de Bush, que buscaba la cooperación y el multilateralismo, marcó un cambio positivo en las relaciones con América Latina, tras del intervencionismo ideológico de la era de Reagan. Esto fue posible, porque el fin de la guerra fría marcó el cierre de la cruzada anticomunista estadounidense de la segunda mitad del siglo XX. Liberados de las gríngolas ideológicas, los líderes estadounidenses pasaron a dar prioridad a asuntos económicos, como la defensa del mercado y el libre comercio.

${ }^{87}$ Johnson 2001.

${ }^{88}$ Pastor 1992:111-112; MacPherson 2006, 108-109 y Rabe 2012: 191-192. 


\section{DESPUÉS DE LA GUERRA FRÍA}

A William J. (Bill) Clinton le tocó el honor de ser el primer presidente posterior a la guerra fría. Clinton lideró a Estados Unidos en un nuevo orden mundial con una clara preeminencia global estadounidense. Esto le permitió lanzar su política de Democratic Enlargement (expansión democrática) que buscaba fortalecer las democracias de mercado existentes, y promoverlas donde no existiesen. La administración Clinton quería mantener el liderato mundial tras el fin de la Guerra Fría y del "peligro comunista", rechazando el intervencionismo y promoviendo el multilateralismo. Con un enfoque wilsoniano, se buscaba promover los intereses económicos estadounidenses y el American way of life. ${ }^{89}$

Una de las prioridades internacionales de Clinton fue la reducción de las barreras comerciales y la expansión del mercado global, la llamada globalización, pues creía que la integración comercial promovería la democracia y la prosperidad a nivel mundial. Fue Clinton quien logró la ratificación del TLCAN negociado por Bush. Su administración usó incentivos económicos para que otras naciones se unieron a la globalización, adoptando el liberalismo económico con la reducción del papel económico del Estado y la integración de los mercados. ${ }^{90}$

Temerosos de caer nuevamente en la marginación frente a la competencia que significaban los recién «liberados» países del este europeo por la ayuda económica, préstamos e inversión de capital, los países latinoamericanos recibieron positivamente el acercamiento de la administración Clinton.

A pesar de que nivel discursivo la política de Clinton parecía marcar un nuevo rumbo, en la práctica, fue poco imaginativa. El presidente expresó poco interés real por sus vecinos latinoamericanos y tuvo muy pocos resultados concretos. ${ }^{91}$ Además, su administración fue víctima de la ignorancia de la historia, las tradiciones y la personalidad latinoamericana.

\footnotetext{
${ }^{89}$ Palmer 2006: 24-42.

${ }^{90}$ Ib.: 45-47.

${ }^{91}$ Ocupado por temas internacionales y domésticos (Yugoslavia, Medio Oriente, seguridad social, etc.) América Latina no fue una prioridad para Clinton. Prueba de ello es
} 
Fue Clinton quien convocó la Cumbre de las Américas, la primera reunión interamericana con participación estadounidense desde la conferencia de Punta del Este en 1964. Los 33 líderes americanos que se reunieron en Miami en diciembre de 1994, acordaron crear una zona de libre comercio hemisférica para el año 2005. De haberse concretado el Área de Libre Comercio de las América, se habría creado un mercado de 850 millones de personas, pero no se logró por la oposición de diversos sectores de la sociedad estadounidense. ${ }^{92}$ En 1997, el Congreso de los EEUU le negó a Clinton la vía "fast-track" para la aprobación del tratado de libre comercio con Chile por la oposición de los sindicatos y los ambientalistas. ${ }^{93}$

La administración Clinton no produjo nada verdaderamente decisivo en su política hacia América Latina. Clinton se ganó la reputación de indeciso e inconsistente, pues prometió mucho, pero cumplió poco.

\section{CONCLUSIÓN}

Nuestro análisis general de las relaciones de Estados Unidos y América Latina nos permite llegar a varias conclusiones. En primer lugar, es muy difícil para una potencia mundial combinar la defensa de sus intereses económicos y geopolíticos con el deseo o la estrategia de ser un buen vecino. Como vimos, a lo largo del siglo XX hubo varios intentos sinceros del gobierno estadounidense para mejorar sus relaciones con América Latina, promoviendo el progreso económico y la estabilidad política entre sus vecinos meridionales. Las buenas intenciones estadounidenses fueron bien recibidas por los estados latinoamericanos, ávidos de una relación más balanceada con su poderoso vecino. Los latinoamericanos esperaban de los estadounidenses un acercamiento multilateral a los problemas de la región, el fin de a la intervención directa e indirecta de Estados Unidos en sus asuntos internos, y apoyo para su desarrollo económico. Sin embargo,

que su primer viaje a América Latina fue en 1997, cuando visitó a México. Clinton fue el primer presidente de la segunda mitad del siglo XX que no viajó a América Latina en su primer término en la Casa Blanca.

92 McPherson 2006: 118.

${ }^{93}$ Esta vía daba al presidente el poder de negociar tratados que podían ser rechazados o aprobados por el Congreso sin enmienda o filibusterismo. 
la inmensa mayoría de las iniciativas estadounidenses fracasaron, o se quedaron a medias, liquidadas por prioridades geopolíticas y presiones económicas. En otras palabras, mantener a Alemania fuera del Caribe a principios del siglo XX o defender los intereses de compañías mineras estadounidenses en Chile durante los años 1970, fueron factores más importantes que el deseo de ser un buen vecino.

Queda claro que los prejuicios raciales y las limitaciones ideológicas jugaron un papel determinante en el desarrollo de las relaciones de Estados Unidos y América Latina a largo de todo el siglo XX. Desde el racismo de Teodoro Roosevelt, hasta el anticomunismo rabioso de Ronald Reagan, la política estadounidense hacia la región estuvo, por periodos, deformada por ideas preconcebidas, fundamentadas en prejuicios, teorías conspiratorias y suposiciones erradas. Ello llevó a los policymakers estadounidenses a cometer costosos errores que entorpecieron sus intenciones de promover el progreso económico, la democracia y la estabilidad política entre los países latinoamericanos.

Los intentos de los líderes estadounidenses de ser buenos vecinos estuvieron seriamente limitados por su ignorancia en asuntos latinoamericanos, especialmente con relación a la historia y la cultura de la región. También mostraron una impresionante incapacidad para aprovechar el conocimiento y la experiencia de aquellos versados en temas latinoamericanos. Una de las principales fallas de los estadounidenses con relación a sus vecinos latinoamericanos fue no preocuparse de entender ni respetar las particularidades sociales, económicas y políticas de la región. Históricamente, la gran mayoría de los líderes estadounidenses no han sido capaces de entender que América Latina no es un ente uniforme, sino un organismo complejo y variado.

Motivadas principalmente por factores económicos y geopolíticos, las buenas intenciones estadounidenses han fracasado, víctimas de los prejuicios raciales, los determinismos ideológicos, las prioridades geopolíticas, los intereses económicos y, especialmente, el desconocimiento de la historia, la cultura, las estructuras sociales y las dinámicas políticas de los países latinoamericanos. En palabras de Lawrence S. Eagleburger, último secretario de Estado de la administración Bush: 
No negaré que mi país tiene su parte de responsabilidad por tender a ver nuestras relaciones continentales a través del prisma, a veces deformante, de la guerra fría [...] Pero cometimos errores, y el más serio fue la ocasional incapacidad de tomar a nuestro continente en sus propios términos y afrontar sus problemas por derecho propio. ${ }^{94}$

En conclusión, en el desarrollo de las relaciones internacionales no basta con tener buenas intenciones.

\section{BIBLIOGRAFÍA}

Benjamin, Jules R. 1990. The United States and the Origins of the Cuban Revolution: An Empire of Liberty in an Age of National Liberation. Princeton, N.J.: Princeton University Press.

Colby, Jason M. 2011. The Business of Empire: United Fruit, Race, and U.S. Expansion in Central America. Ithaca: Cornell University Press.

Cooper, J. M. (ed.). 2008. Reconsidering Woodrow Wilson: Progressivism, Internationalism, War, and Peace. Washington, D.C.: Woodrow Wilson Center Press.

Cramer, Gisela y Ursula Prutsch (eds.). 2012. ¡Americas unidas! Nelson A. Rockefeller's Office of Inter-American Affairs (1940-1946). Madrid: Iberoamericana, Vervuet. https://doi.org/10.31819/9783954870110

Dallek, Robert. 1995. Franklin D. Roosevelt and American Foreign Policy, 1932-1945. New York \& Oxford: Oxford University Press.

Danner, Mark. 1994. The Massacre at El Mozote a Parable of the Cold War. New York: Vintage Books.

Dyer, Thomas. 1980. Theodore Roosevelt and the Idea of Race. Baton Rouge and London: Louisiana State University Press.

Field, Thomas C. Jr. 2014. From Development to Dictatorship: Bolivia and the Alliance for Progress in the Kennedy Era. Ithaca \& London: Cornell University Press. https://doi.org/10.7591/cornell/9780801452604.001.0001

Gilderhus, Mark T. 2000. The Second Century: U. S. - Latin American Relations since 1889. Delaware: Scholarly Resources Inc.

Gleijeses, Piero. 1991. Shattered Hope: The Guatemalan Revolution and the United States, 1944-1954. Princeton, N.J.: Princeton University Press.

Grandin, Greg. 2004. The Last Colonial Massacre: Latin America in the Cold War. Chicago \& London: The University of Chicago Press. https://doi.org/10.7208/ chicago/9780226306872.001.0001

${ }^{94}$ Raymont 2005: 329. 
Harmer, Tanya. 2011. Allende's Chile and the Inter-American Cold War. Chapel Hill: The University of North Carolina Press. https://doi. org/10.5149/9780807869246_harmer

Hart, John M. 2002. Empire and Revolution: The Americans in Mexico since the Civil War. Berkeley: University of California Press. https://doi.org/10.1525/ california/9780520223240.001.0001

Haslam, Jonathan. 2005. The Nixon Administration and the Death of Allende's Chile: A Case of Assisted Suicide. London \& New York: Verso.

Hawley, Ellis W. 1992. The Great War and the Search for a Modern Order. New York: St. Martin's Press.

Healy, David. 1988. Drive to Hegemony: The United States in the Caribbean, 18981917. Madison: University of Wisconsin Press.

Immerman, Richard H. 1982. The CIA in Guatemala: The Foreign Policy of Intervention. Austin: University of Texas Press.

Johnson, Chalmer. 2001. Blowback: The Costs and Consequences of American Empire. Holt Paperbacks.

Joseph, G. M., Catherine LeGrand, y Ricardo Donato Salvatore. 1998. Close Encounters of Empire: Writing the Cultural History of U.S.-Latin American Relations. Durham: Duke University Press. https://doi.org/10.1215/9780822396352

Joseph, G. M. y Daniela Spenser. 2008. In from the Cold: Latin America's New Encounter with the Cold War. Durham: Duke University Press. https://doi. org/10.1215/9780822390664

Kastor, Peter J. 2010. America's Struggle with Empire: A Documentary History. Washington D.C.: CQ Press.

Kenworthy, Eldon. 1995. America/Américas: Myth in the Making of U.S. Policy toward Latin America. University Park, Pa.: Pennsylvania State University Press.

LaFeber, Walter. 1983. Inevitable Revolutions: The United States in Central America. New York: W. W. Norton \& Company.

1994. The American Age: United States Foreign Policy at home and abroad. New York \& London: W.W. Norton \& Company.

Langley, Lester D. 1983. The Banana Wars an Inner History of American Empire, 1900-1934. Lexington, Kentucky: University Press of Kentucky.

Lindsay-Poland, John. 2003. Emperors in the Jungle: The Hidden History of the U. S. in Panama. Durham: Duke University Press. https://doi. org/10.1215/9780822384601

Longley, Kyle. 2002. In the Eagle's Shadow: The United States and Latin America. Wheeling, Illinois, Harlan Davidson, Inc.

Loveman, Brian. 2006. Addicted to Failure: U.S. Security Policy in Latin America and the Andean Region. Lanham, Md.: Rowman \& Littlefield Publishers.

Lynch, Edward A. 2011. The Cold War's Last Battlefield: Reagan, the Soviets, and Central America. State University of New York Press. 
Marks, Frederick W III. 1988. Wind Over Sand: The Diplomacy of Franklin D. Roosevelt. Georgia: University of Georgia Press.

McCullough, David. 1977. The Path Between the Seas: The Creation of the Panama Canal, 1870-1914. New York: Simon \& Schuster.

McPherson, Alan L. 2003. Yankee No!: Anti-Americanism in U.S.-Latin American Relations. Cambridge, Mass.: Harvard University Press.

2006. Intimate Ties, Bitter Struggles: The United States and Latin America since 1945. Washington, D.C.: Potomac Books.

McSherry, J. Patrice. 2009. Los estados depredadores: la Operación Cóndor y la guerra encubierta en América Latina. Santiago de Chile: LOM Ediciones.

Morales Carrión, Arturo. 2003. Puerto Rico y la lucha por la hegemonía en el Caribe: Colonialismo y contrabando, siglos XVI-XVIII. San Juan: Centro de Investigaciones Históricas, Editorial de la Universidad de Puerto Rico.

Morgenfeld, Leandro. 2011. Vecinos en conflicto: Argentina y Estados Unidos en las Conferencias Panamericanas, 1880-1955. Buenos Aires: Peña Lillo y Ediciones Continente.

Munro, Dana Gardner. 1980. Intervention and Dollar Diplomacy in the Caribbean, 1900-1921. Westport, Conneticut: Greenwood Press.

Nieto, Clara. 2005. Los amos de la guerra. El intervencionismo de Estados Unidos en América Latina. De Eisenhower a G. W. Bush. Barcelona: Debate.

O'Brien, Thomas. 1996. The Revolutionary Mission: American Enterprise in Latin America, 1900-1945. Cambridge: Cambridge University Press.

Offiler, Benjamin. 2010. «The Alliance for Progress during the Kennedy and Johnson Administrations: Laudable idea, poorly implemented?». 49th Parallel. Volumen 24: 1-22. http://www.49thparallel.bham.ac.uk/back/issue24/Offiler.pdf.

Palmer, David Scott. 2006. U.S. Relations with Latin America during the Clinton Years: Opportunities Lost or Opportunities Squandered. Gainesville: University Press of Florida.

Pastor, Robert A. 1992. Whirlpool: U. S. Foreign Policy Toward Latin America and the Caribbean. Princeton: Princeton University Press.

Paterson, Thomas G. 1994. Contesting Castro: The United States and the Triumph of the Cuban Revolution. New York: Oxford University Press.

Perez, Louis A. Jr. 1999. «Incurring a Debt of Gratitude: 1898 and the Moral Sources of United States Hegemony in Cuba». The American Historical Review. Volumen 104, número2: 356-398. https://doi.org/10.2307/2650370

Rabe, Stephen G. 1978. «The Elusive Conference: United States Economic Relations with Latin America, 1945-1952». Diplomatic History. Volumen 2, número 3: 279-294. https://doi.org/10.1111/j.1467-7709.1978.tb00436.x

1988. Eisenhower and Latin America: The Foreign Policy of Anticommunism. Chapel Hill \& London: The University of North Carolina Press. 
2012. The Killing Zone: The United States Wages Cold War in Latin America. Oxford University Press.

Raymont, Henry. 2005. Vecinos en conflicto: La historia de las relación entre Estados Unidos y Latinoamérica desde FDR hasta nuestros días. México, D.F.: Siglo XXI.

Rivas, Darlene. 2002. Missionary Capitalist: Nelson Rockefeller in Venezuela. Chapel Hill: University of North Carolina Press.

Roorda, Eric. 1998. The Dictator Next Door: The Good Neighbor Policy and the Trujillo Regime in the Dominican Republic, 1930-1945. Durham: Duke University Press. https://doi.org/10.1215/9780822398325

Schlesinger, Stephen y Stephen Kinzer. 1982. Bitter Fruit: The Untold Story of the American Coup in Guatemala. Garden City, N.Y.: Doubleday.

Schmidli, William Michael. 2011. «Institutionalizing Human Rights in U.S. Foreign Policy: U.S.-Argentine Relations, 1976-1980». Diplomatic History. Volumen 35, número 2: 351-377. https://doi.org/10.1111/j.1467-7709.2010.00951.x .2012. «Human rights and the Cold War: the campaign to halt the Argentine 'dirty war'». Cold War History. Volumen 12, Número 2: 345-365. https://doi. org/10.1080/14682745.2011.569540

Schoultz, Lars. 1998. Beneath the United States: A History of U.S. Policy toward Latin America. Cambridge, Mass.: Harvard University Press.

Smith, Gaddis. 1994. The Last Years of the Monroe Doctrine, 1945-1993. New York, Hill and Wang.

Smith, Peter. 1999. Talons of the Eagle: Dynamics of US-Latin American Relations. New York/Oxford: Oxford University Press.

Stokes, Doug. 2003. «Countering the Soviet Threat? An Analysis of the Justifications for US Military Assistance to El Salvador, 1979-92». Cold War History. Volumen 3, número 3: 79-102. https://doi.org/10.1080/14682740312331391628

Striffler, Steve y Mark Moberg. 2003. Banana Wars Power, Production, and History in the Americas. Durham: Duke University Press. https://doi. org/10.1215/9780822385288

Suárez Salazar, Luis y Tania García. 2008. Las relaciones interamericanas: continuidades y cambios. Buenos Aires: Consejo Latinoamericano de Ciencias Sociales (CLACSO).

Thompson, Lanny. 2010. Imperial Archipelago: Representation and the Rule in the Insular Territories Under U.S. Dominion After 1898. Hawaii: University of Hawaii Press. https://doi.org/10.21313/hawaii/9780824834012.001.0001

Veeser, Cyrus. 2002. A World Safe for Capitalism: Dollar Diplomacy and America's Rise to Global Power. New York: Columbia University Press.

Westad, Odd Arne. 2007. The Global Cold War: Third World Interventions and the Making of Our Times. Cambridge: Cambridge University Press.

Wilson, Woodrow. 1913. "Address Before the Southern Commercial Congress in Mobile, Alabama, October 27, 1913». The American Presidency Project. http:// 
www.presidency.ucsb.edu/ws/?pid=65373. Fecha de consulta: 27 de setiembre de 2018.

Youngers, Coletta A. y Eileen Rosin. 2005. Drogas y democracia en América Latina. El impacto de la política de Estados Unidos. Buenos Aires: WOLA, Editorial Biblos.

Zahnizer Marvin R., y W. Michael Weis, 1989. «A Diplomatic Pearl Harbor? Richard Nixon's Goodwill Mission to Latin America in 1958». Diplomatic History. Volumen 13, número 2: 163-190. https://doi.org/10.1111/j.1467-7709.1989. tb00050.x

Zaretsky, Natasha. 2011. «Restraint or Retreat? The Debate over the Panama Canal Treaties and U.S. Nationalism after Vietnam». Diplomatic History. Volumen 35, número 3: 535-562. https://doi.org/10.1111/j.1467-7709.2011.00962.x

Fecha de recepción: 17/IV/2019

Fecha de aceptación: 6/VI/2019 